OPEN ACCESS

Edited by:

Xiubin Lin,

Zhejiang University, China

Reviewed by:

$X i X u$,

China Aero Geophysical Survey and Remote Sensing Center for Natural

Resources, China

Bo Yang,

Zhejiang University, China

*Correspondence: Junling Pei

junlingpei@163.com

Specialty section:

This article was submitted to Structural Geology and Tectonics, a section of the journal

Frontiers in Earth Science

Received: 20 September 2021

Accepted: 27 October 2021

Published: 25 November 2021

Citation:

Wu Y, Pei J, Wang Z, Zhang $Y$ and Yuan $H$ (2021) Analysis on the Characteristics of Crustal Structure and Seismotectonic Environment in

Zigui Basin, Three Gorges.

Front. Earth Sci. 9:780209.

doi: $10.3389 /$ feart.2021.780209

\section{Analysis on the Characteristics of Crustal Structure and Seismotectonic Environment in Zigui Basin, Three Gorges}

\author{
Yunlong $W^{1,2,3}$, Junling Pei ${ }^{4,5 *}$, Ze Wang ${ }^{6}$, Yi Zhang ${ }^{1,2}$ and Huaqing Yuan ${ }^{1,2}$ \\ ${ }^{1}$ Key Laboratory of Earthquake Geodesy, Institute of Seismology, China Earthquake Administration, Wuhan, China, ${ }^{2}$ Hubei \\ Earthquake Administration, Wuhan, China, ${ }^{3}$ College of Disaster Prevention Science and Technology, College of Geological \\ Engineering, Sanhe, China, ${ }^{4}$ Institute of Geomechanics, Chinese Academy of Geological Sciences, Beijing, China, ${ }^{5}$ Key \\ Laboratory of Paleomagnetism and Tectonic Reconstruction, The Ministry of Land and Resources, Beijing, China, ${ }^{6}$ GNSS \\ Research Center, Wuhan University, Wuhan, China
}

The Zigui Basin in the Three Gorges area is a syncline running in the north-south axial direction; the sediments in the basin are mainly late Triassic-late Jurassic sandy and argillaceous rocks. Since the Three Gorges Project began undergoing impoundment in May 2003, nearly 20,000 mini-earthquakes have occurred in the Zigui-Badong region, including five earthquakes with magnitudes greater than Ms 5.0. Herein, a 3D gravity inversion method was introduced to investigate the density structure of the Zigui Basin and its adjacent areas. A comprehensive analysis of the geological structure of the area was carried out, based on focal mechanism solutions of six moderate-strong earthquakes in the area. The Zigui Basin is a low-density area from the periphery, and the sediment in the east is thicker but less dense than in the west. The shallow part of the Zigui Basin is a weak bottom layer prone to slippage, and the deep part (5-10 km) could comprise lithological strata such as limestone, sandstone, and shale, which easily undergo dissolution by leaking reservoir water. Under the action of external forces such as long-term infiltration and unloading of reservoir water, fissures will expand and squeeze then earthquakes are likely induced in the deep strata. Furthermore, new buried faults in the western and southeastern edges of the core area of the Zigui Basin could also trigger an earthquake under long-term pressurization and reservoir water penetration.

Keywords: gravity analysis, 3D gravity inversion, Three Gorges area, Zigui basin, density structure

\section{INTRODUCTION}

The Zigui Basin in the Three Gorges area is located in the thin-skinned structural zone of Chongqing City, Hunan and Hubei Province, with the Yangtze Plate to the south, the Qinling Orogenic Belt to the north, the Sichuan Basin in the west, and the Huangling Anticline in the east. The entire area is squeezed by the Qinling Mountains and Xuefeng Mountains from north to south. The earthquakes in this area are contributed by a unique geological environment that the Three Gorges Reservoir has been in a state of infiltration for many years due to the slippage and folding of the weak sedimentary layer of the rocks in the area. (Li et al., 1987; Wang K. et al., 2013; Wang J. et al., 2018; Wang W. et al., 2018). According to records, there were two significant destructive earthquakes at the Zigui-Badong region in history: the Ms 5.1 Zigui Longhuiguan earthquake in 1979 and the Ms 5.1 Badong earthquake in 2013. Since the impoundment of the Three Gorges in May 2003, 4 Ms 4.0-4.9 earthquakes have occurred, 
accompanied by a large number of mini earthquakes with high frequency and low magnitude. This is worthy of in-depth study, as the frequent occurrence of earthquake activities is closely related to the special geological structure background and the water permeability of the Three Gorges Reservoir (Li et al., 2010; Wang Q. et al., 2013; Zhang et al., 2017).

Focusing on the complex geological structure and geophysical background of the Three Gorges area, many scholars have conducted extensive research in this area over the years. The analysis of rock thermal tectonic evolution in this area suggests that the Cretaceous and Cenozoic activation of the Qinling-Dabie Orogenic Belt in the North China and Yangtze Craton is the result of the Pacific subduction-North China back arc extension (Hu et al., 2006a; Hu et al., 2006b; Ge et al., 2013). The Yangtze Plate and the North China Plate collided with the orogenic belt in the late Middle Triassic to form the Qinling-Dabie Orogenic Belt, which in turn affected the periphery of the Yangtze Plate, and the Zigui Basin gradually changed from a marine basin to a foreland basin (Liu et al., 2005; Liu et al., 2015a). Throughout the Mesozoic sedimentary process, the basin underwent a northward, north-eastward, and eastward shift in the sediment source, corresponding to changes in paleocurrent in the southern Qinling Mountains (Liu et al., 2005; Shen C.-B. et al., 2012; Shen C. et al., 2012). The complex geological evolution has resulted in the unique geological environment in the Zigui Basin.

Since the construction of the Three Gorges Dam, there have been many studies on the gravity field and crustal deformation in response to changes in water storage in the Three Gorges and adjacent areas (Zhang et al., 1996; Wang et al., 2002; Wang et al., 2014). The relationship between the subsurface fault distribution and seismic coupling has been discussed using the Bouguer gravity and aeromagnetic anomalies, as well as the seismic sources distribution (Liu et al., 1984; Shen et al., 1990). Some scholars have also used the Bouguer gravity anomaly to investigate the crustal structure and the Moho depth of the Three Gorges area to obtain the layered structure of the crust in the area, and discuss the tectonic significance in the area with the regional faults (Li et al., 1987; Wang et al., 1992; Wang et al., 2012). Li et al. (2011) used seismic $P$ and $S$ wave arrival data and tomography method to obtain the 3D crustal velocity structure of the region, which provided new insights into the development and evolution of deep structures in the Three Gorges area.

Previous research has shown that the preparation and occurrence of earthquakes are related to the distribution and activity of underground fault structures. While the distribution and changes in the density of the Earth's crust can be considered to reflect the underground material migration, no study has been carried out to analyze the evolution of underground material migration against the background of geological formations and, furthermore, to analyze the relationship between regional faults and seismic tectonics coupling with natural seismic events (Li et al., 1987; Li et al., 2010; Wang K. et al., 2013; Wang Q. et al., 2013; Zhang et al., 2017). In this study, a 3D gravity inversion method with a Lagrange multiplier (Zhang et al., 2015) was introduced to determine the crustal density distribution with the constraints of prior local geological and geophysical information. Combining the focal mechanism solution of the six moderate earthquakes and the geological evolution background, the seismogenic structure and faults distribution in the area were analyzed.

\section{GEOLOGICAL BACKGROUND OF ZIGUI BASIN AND ITS PERIPHERY IN THE THREE GORGES}

Zigui basin of the Three Gorges in Western Hubei is an important tectonic unit in the Yangtze River area. This area is a Mesozoic tectonic basin that developed and formed in the late Triassic and early Jurassic eras and is mainly composed of Jurassic continental facies and middle-upper Triassic coastal facies clastic rocks (Yu et al., 2017). As shown in Figure 1, the stratigraphic outcrop in the area is relatively complete, Proterozoic dominated by Kongling Group, Shenlongjia Group, and Sinian; Paleozoic dominated by Cambrian, Ordovician, Silurian, Devonian, Carboniferous, and Permian; Mesozoic dominated by Triassic, Jurassic, and Cretaceous; and Cenozoic dominated by Quaternary are all exposed. Large areas of western and southern parts of the basin consist of marine carbonate sedimentary strata, while the eastern part is dominated by carbonate rocks with fine clastic rocks. The Huangling Anticline in the east and the Shennongiia Uplift in the north are mainly composed of gneiss, mixed rock, and granite in the Proterozoic Kongling Group (Qu et al., 2009).

The rock distributions and their density parameters are shown in Table 1. Gneiss and dolomite-dominated carbonate rocks are low-density materials with densities of approximately $2.58-2.74 \mathrm{~g} /$ $\mathrm{cm}^{3}$, while dolomites, granites and metamorphic complexes are high-density materials with a density of approximately $2.72-3.2 \mathrm{~g} /$ $\mathrm{cm}^{3}$. In this work, the rock density constraints in Table 1 were used to carry out the gravity inversion.

As shown in Figure 2, the Badong-Zigui region is located in a low-medium mountainous area with deep canyons. The fault structures in the area are mainly NE- and NW-oriented, such as the NNE-directed Xinhua-Shuitianba fault and Niukou-Zhoujiashan fault, NE-directed Gaoqiao fault, NWdirected Wuduhe fault and Tianyangping fault, NNW-directed Xiannvshan fault, and EW-directed Maluchi fault. In terms of earthquake distribution, small-medium earthquakes in the Badong-Zigui region are concentrated in the Gaoqiao, Zhoujiashan, and Xiannvshan faults. 2 Ms 5.1 earthquakes have occurred near Xietan, and some studies took the Zhoujiashan fault into account as the seismogenic structure of the Zigui Longhuiguan Ms 5.1 earthquake in 1979 (Wuhan Earthquake Engineering Research Institute, 2010). From a spatial point of view, the smallmedium earthquakes in this area are mainly concentrated in the wedge-shaped tectonic unit formed by the abovementioned faults.

\section{D GRAVITY INVERSION METHOD}

The algorithm adopted in this work is based on the 3D gravity inversion method developed originally by Li and Oldenburg (1996, 1998); Oldenburg (1974). With the addition of the Lagrange multiplier, prior geological and geophysical information can be processed during the inversion by Zhang et al. (2015). The algorithm effectively reduces the problems of ill-posed and multi-solution in the gravity inversion and also improves the quality of the results.

The study area was divided into a series of rectangular units with constant density. Inversion is a process of iterations to 


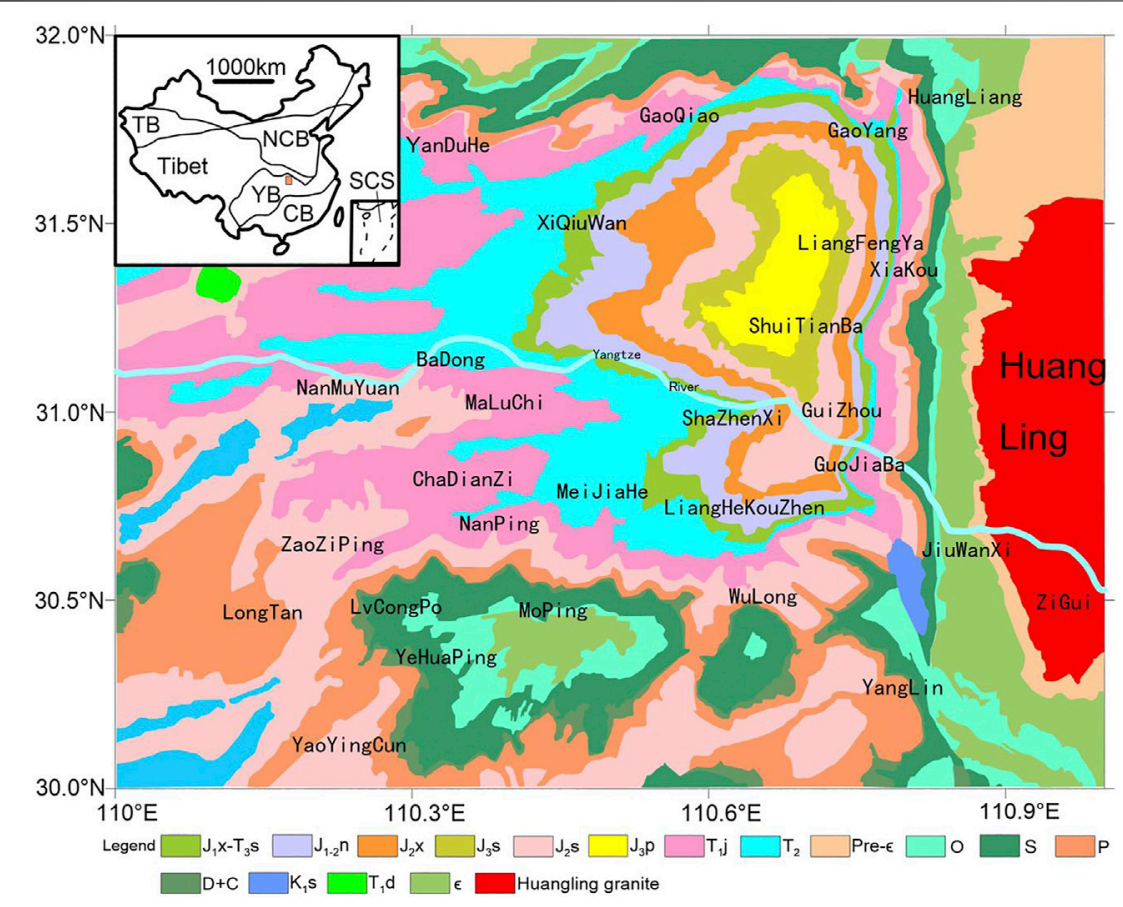

FIGURE 1 | Geographic location and the tectonic map of the Three Gorges reservoir area [from Zhang et al. (2018). J1x-T3s: Lower Jurassic (Xiangxi Formation)Upper Triassic (Shazhenxi Formation), J1-2n: Middle Jurassic (Niejiashan Formation), J2x: Lower Jurassic (Shaximiao Formation), J3s: Upper Jurassic (Suining Formation), J2s: Upper Jurassic (Shaximiao Formation), J3p: Jurassic (Penglai Town Formation), T1j: Lower Triassic (Jialingiiang Formation), T2: Middle Triassic, Pre-ع: Precambrian, O: Ordovician, S: Siluric, P: Permian, D+C: Devonian-Carboniferous, K1s: Cretaceous (Shimen Formation), T1d: Lower Triassic (Daye Formation), ع: Cambrian].

TABLE 1 | Stratigraphic distribution and lithologic parameters in Badong-Zigui region.

\section{Locations}

Western and southern of ZGB

Eastern of ZGB

Northern of ZGB

SLJU area

HLA area

\section{Lithology and density}

parameters

Marine carbonate sedimentary strata of the Middle-Lower Triassic Daye Formation, Jialingjiang Formation, and Badong Formation are exposed (Qu et al., 2009), with a density of approximately $2.6-2.9 \mathrm{~g} / \mathrm{cm}^{3}$

Sedimentary strata, dominated by carbonate rocks (i.e., dolomite), mixed with fine clastic rocks (Qu et al., 2009), with a density of approximately $2.58-2.75 \mathrm{~g} / \mathrm{cm}^{3}$

Mainly Paleozoic marine strata (Qu et al., 2009), with a density of approximately $2.62-2.68 \mathrm{~g} / \mathrm{cm}^{3}$

Mainly the Mesoproterozoic and Paleozoic erathem, dominated by the marine carbonate rocks (i.e., dolomite), pyroclastic rocks, tuffaceous sandstones, and shales (Li et al., 2009; Liu et al., 2016), with a density of approximately $2.7-2.9 \mathrm{~g} / \mathrm{cm}^{3}$ Mainly the Huangling granite, Proterozoic Kongling gneiss, and metamorphic complexes (Qu et al., 2014; Liu et al., 2015b), with the density of gneiss and granite being approximately $2.5-2.8 \mathrm{~g} / \mathrm{cm}^{3}$ and $2.73-3.2 \mathrm{~g} / \mathrm{cm}^{3}$, respectively

obtain the optimal solution. Eq. 1 is the objective function proposed by Li and Oldenburg $(1996,1998)$ :

$$
\min : \phi(\boldsymbol{m})=\phi_{d}+\boldsymbol{\mu} \phi_{m}
$$

where $\varphi_{d}$ is the data misfit, the differences between the observations and the forward values of inversion results; $\varphi_{m}$ is the model objective function, and $\mu$ is the regularization parameter used to balance the weight of the two items.

Based on the abovementioned inverted objective function, geological constraints are imposed on each grid cell, and a slack variable function is introduced (Zhang et al., 2012; Zhang et al., 2015),

$$
s_{i}(m, z)=s_{i}(m)+z_{i}^{2}=0
$$

where $s_{i}(m)$ is a constraint function to deal with the bound constraints in the inversion, and $z_{i}$ denotes the slack variables used to convert the upper or lower bound into equal constraints. the Lagrange multiplier and penalty function were further introduced to obtain the objective function:

$$
\begin{aligned}
\min : \boldsymbol{F}(\boldsymbol{m}, \boldsymbol{z})= & \phi(\boldsymbol{m})+\sum_{i=1}^{N_{Z}} \lambda_{i}\left[s_{i}(\boldsymbol{m})+z_{i}^{2}\right] \\
& +\frac{1}{2} \boldsymbol{M} \sum_{i=1}^{N_{Z}}\left[s_{i}(\boldsymbol{m})+z_{i}^{2}\right]^{2}
\end{aligned}
$$




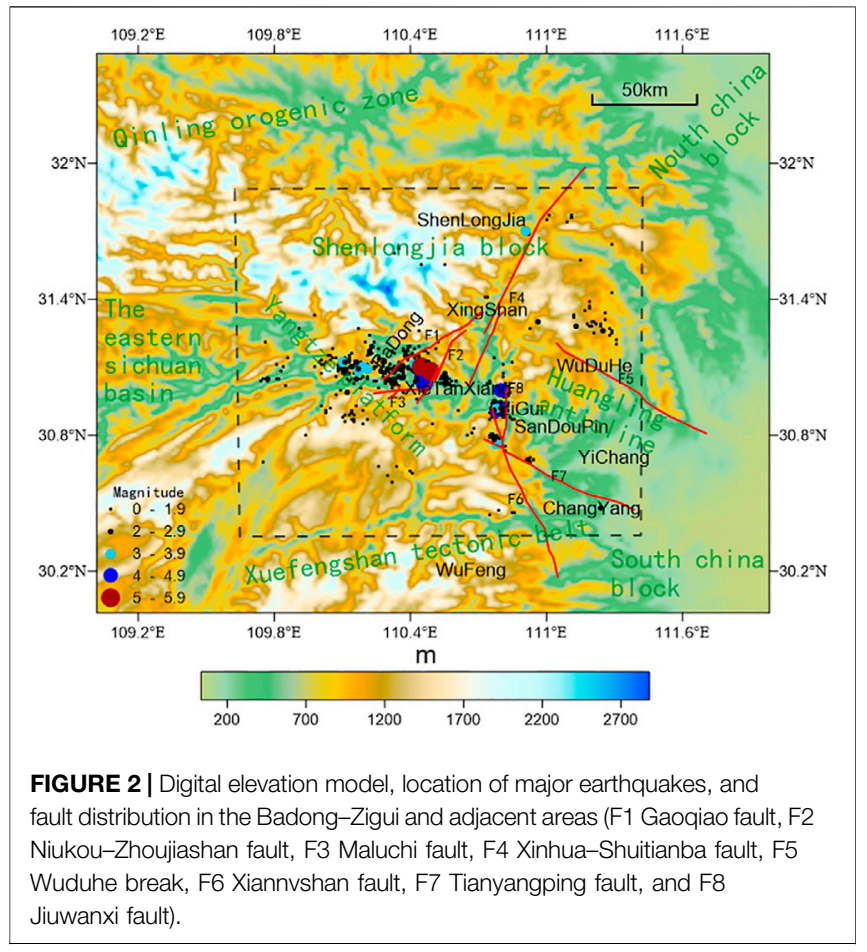

where $\lambda, M$, and $N z$ denote the Lagrange multiplier, the penalty function, and the number of slack variables, respectively. In each step of the iteration, the density and slack variables were calculated simultaneously.

\section{GRAVITY DATA AND PREPROCESSING}

Figure 3 shows the Bouguer gravity anomaly in Badong-Zigui region and its adjacent area. The data were obtained from the China Geological Survey, with a scale of 1:200,000. As shown from the map, Badong and its adjacent areas are located on the Taihang-Wuling gravity gradient belt extending in an NNE direction. The Bouguer gravity is a negative anomaly as a whole, and the anomaly values gradually increase from NW to SE, showing a SE-NW arc-shaped distribution (Yang et al., 2014; Liang et al., 2016). On the Shiyan-Baokang-Zigui-Wufeng line, the Bouguer gravity contours are dense and on the east and west sides away from the gravity gradient belt, the anomaly contours tend to be gentle, mostly in the form of local closed circles. The existence of the entire NNE-trending gravity gradient belt indicates that there is a large-scale structural variation zone in the depth. Since the Neotectonic period, the entire area has been characterized by large, continuous arched uplifts. The modern topographical structure and shallow source earthquakes are controlled by the faults in the area (Li et al., 1987).

The depth change of the Moho surface in the inversion area is relatively gentle. The least squares polynomial fitting method takes the minimum sum of squared residuals as the judgment criterion. It is a suitable method for an area with small extent and simple geological conditions (Zeng, 2005). We adopted the fifth- order least squares polynomial fitting method (Zeng, 2005) to separate the Bouguer gravity into regional (Figure $4 \mathrm{~A}$ ) and local anomalies (Figure 4B). The regional anomaly (Figure 4A) basically corresponds to the Moho variation in this area (Jiang, 2004; Liang et al., 2016). It can be clearly seen that the Moho in this area gradually tilts from east to west. The large negative gravity anomaly in the area of Pingli-Zhenping-Wuxi indicates that there might be roots under the Daba Mountain Range.

In the inversion area, the negative gravity anomaly was caused by the sediments in the Zigui Basin during late Triassic to late Jurassic; to the east of the basin, the horseshoe-shaped Huangling Anticline obliquity causes a high gravity anomaly (Figure 4B), as well as the Shennongiia Uplift. According to a previous investigation (Gong et al., 2014), the sediments of the basin are characterized by migration and denudation from the periphery to the basin. And the Zigui Basin is a part of the extension as a transitional bay from the Sichuan Basin to the east into the Three Gorges Region, with the feature of sea-land interaction and land-land facies deposition vertically.

\section{D GRAVITY INVERSION RESULT}

The geometry of the inversion area is $170 \mathrm{~km}$ in both EW and NS directions, and the depth is $30 \mathrm{~km}$. During the 3D constraint inversion, because the objective function Eq. 3 is an ill-posed problem, the larger the vector $\mathbf{m}$, the more serious the nonuniqueness of inversion. Through a lot of experiments (Wang, 2020 ), we divided the inversion region into $34 \times 34 \times 15$ rectangular grids with a single grid size of $5 \times 5 \times 2 \mathrm{~km}^{3}$, the inversion time reduced and inversion result was satisfied. According to Eq. 3, the initial value of the penalty factor, the

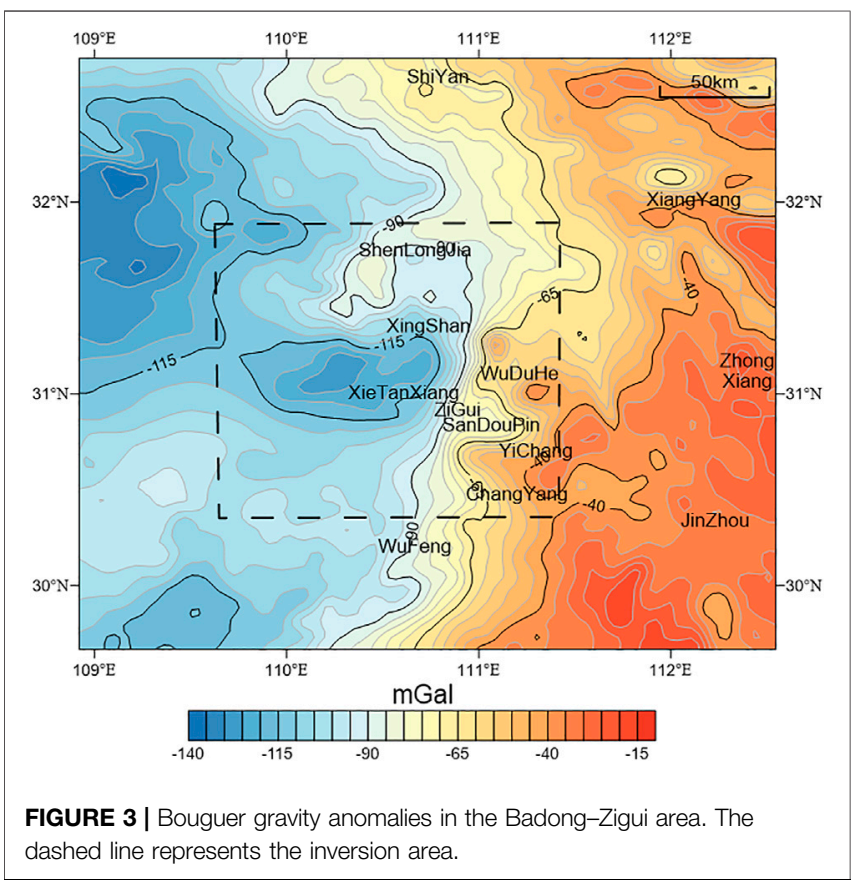



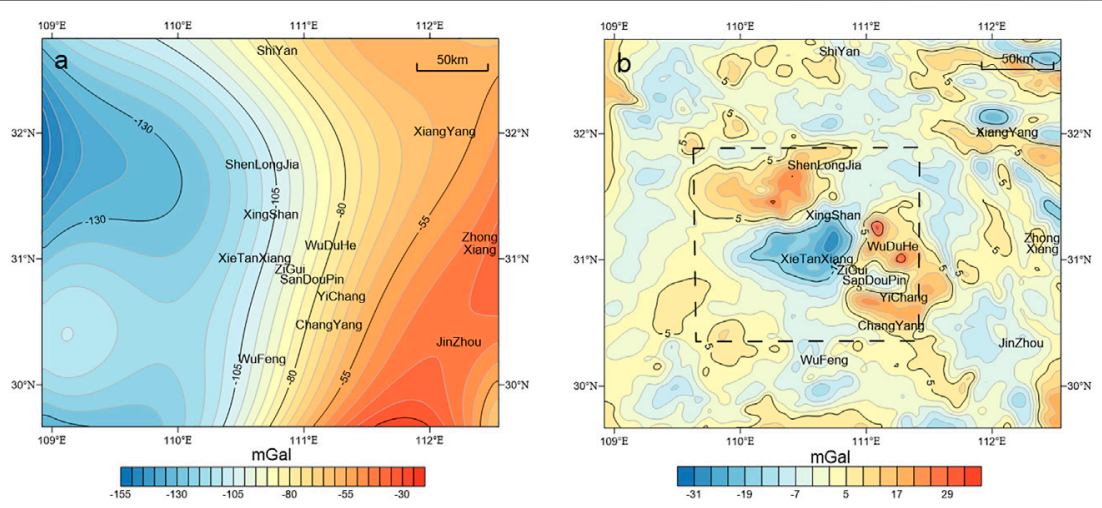

FIGURE 4 | (A) Regional gravity anomalies and (B) local gravity anomalies in the Badong-Zigui area. The dashed line represents the inversion area.

depth weighting function, and the termination criterion were set at $1.0 \times 10^{-6}, 2$, and $1.0 \times 10^{-8}$, respectively. Based on analysis of the geological information of the inversion area in Geological Background of Zigui Basin and its Periphery in the Three Gorges, the lower bound was set uniformly for all inversion grid cells as 2 . $58 \mathrm{~g} / \mathrm{cm}^{3}$, with an upper bound of $2.90 \mathrm{~g} / \mathrm{cm}^{3}$. There is no prior reference model used in the inversion, only a constraint of density with range of $2.58-2.9 \mathrm{~g} / \mathrm{cm}^{3}$. Different regularization parameters were introduced for iteration to obtain the Tikhonov curve (Li and Oldenburger, 1996, 1998; Zhang et al., 2015), and the regularization parameter was selected to balance the model complexity and data misfit at the same time. As a result, the obtained underground density distributions were shown in Figure 5.

The density structure at this depth of $0-2 \mathrm{~km}$ was evenly distributed, there are small areas of low density on the SW side of Badong-Xietanxiang-Zigui, with a density of approximately $2.62-2.64 \mathrm{~g} / \mathrm{cm}^{3}$, and areas of high density on the NE side of Zigui-Sandouping, with a density of approximately 2.67-2.692 g/ $\mathrm{cm}^{3}$. Taking into account the analysis, these two areas should be reflections of the Zigui Basin and the Huangling Anticline at the shallow surface.

The heart-shaped Zigui Basin, horseshoe-shaped Huangling Anticline, and Shenlongjia Uplift are clearly visible. The red highdensity zone in the Wuduhe-Sandouping-Changyang region is the Huangling Anticline with an inversion density of $2.69-2.725 \mathrm{~g} / \mathrm{cm}^{3}$. In its central part, there is an area of low density that approximately encompasses an elliptical region where the Three Gorges Dam is located.

The blue low-density area of the Zigui Basin is a sedimentary layer of Jurassic clasts (Qu et al., 2009) with inversion density ranging from 2.6 to $2.64 \mathrm{~g} / \mathrm{cm}^{3}$. The seismogenic mechanism with high frequency and low magnitude is mainly found in the sediment layer of the Zigui Basin. In the middle of Zigui and Huangling, a large number of tremors are concentrated, and $2 \mathrm{Ms}$ $\geq 4.0$ earthquakes have occurred. The induction of these earthquakes may be related to the slow uplift of the Huangling Anticline at slow uplift and the relative subsidence of the Zigui Basin. On December 16, 2013, an Ms 5.1 earthquake occurred in Badong, with the epicenter shown as the red dot in the figure. In the west of the epicenter, an Ms 5.1 earthquake also occurred in Longhuiguan. This indicates strong tectonic movement in the Zigui Basin. The high-density area in the northwestern part of the basin is the Shenlongjia Uplift, which is a large anticline. It is a geologic structure dominated by carbonate rocks interspersed with multiple layers of clastic layers, with an inversion density of $2.69-2.72 \mathrm{~g} / \mathrm{cm}^{3}$.

The profiles of the Zigui Basin and Huangling Anticline in Figure 5C show similar patterns to those in Figure 5B. The inversion density values of the Huangling Anticline and the Shenlongiia Uplift decrease compared with those in Figure 5B, with density values ranging from 2.69 to $2.705 \mathrm{~g} /$ $\mathrm{cm}^{3}$, indicating a gradual shallowing of the base of the two anticlines. The density of the Zigui Basin is $2.62-2.64 \mathrm{~g} / \mathrm{cm}^{3}$, and the density in the area around Xingshan is smaller than that around Badong. It indicates that the basin sedimentation is uneven. Most earthquakes in this depth region are concentrated in the Huangling Anticline and the middle of the basin and the western margin of the basin.

The Shenlongjia Uplift, Huangling Anticline, and Zigui Basin are still clearly delineated in Figure 5D. The density value of the Huangling Anticline is around $2.675-2.69 \mathrm{~g} / \mathrm{cm}^{3}$, and the amplitude decreases significantly compared to Figures 5B,C. The crystalline substrate is further accentuated. The outline of the Zigui Basin is significantly reduced, with density values of approximately $2.63-2.65 \mathrm{~g} / \mathrm{cm}^{3}$, and the sedimentary base is basically prominent and close to the surrounding density nearby Badong. The density values are small near Xingshan, showing that the Zigui Basin deepens from west to east. According to previous geological studies, a NE-oriented ancient river exists between the Huangling and Shenlongiia Uplift in the direction of Xinhua-Xingshan, which continuously provides material for the sedimentary filling of the basin from NE to SE (Gong et al., 2014). This may be responsible for the lower density and deeper basement in the eastern part of the basin compared to the western part, and the sedimentary material in the western part of the basin should also have been eroded from the eastern Xingshan-Xinhua area.

The bottoms of the two tectonic units, the Zigui Basin and the Huangling Anticline, are shown to reach essentially the 


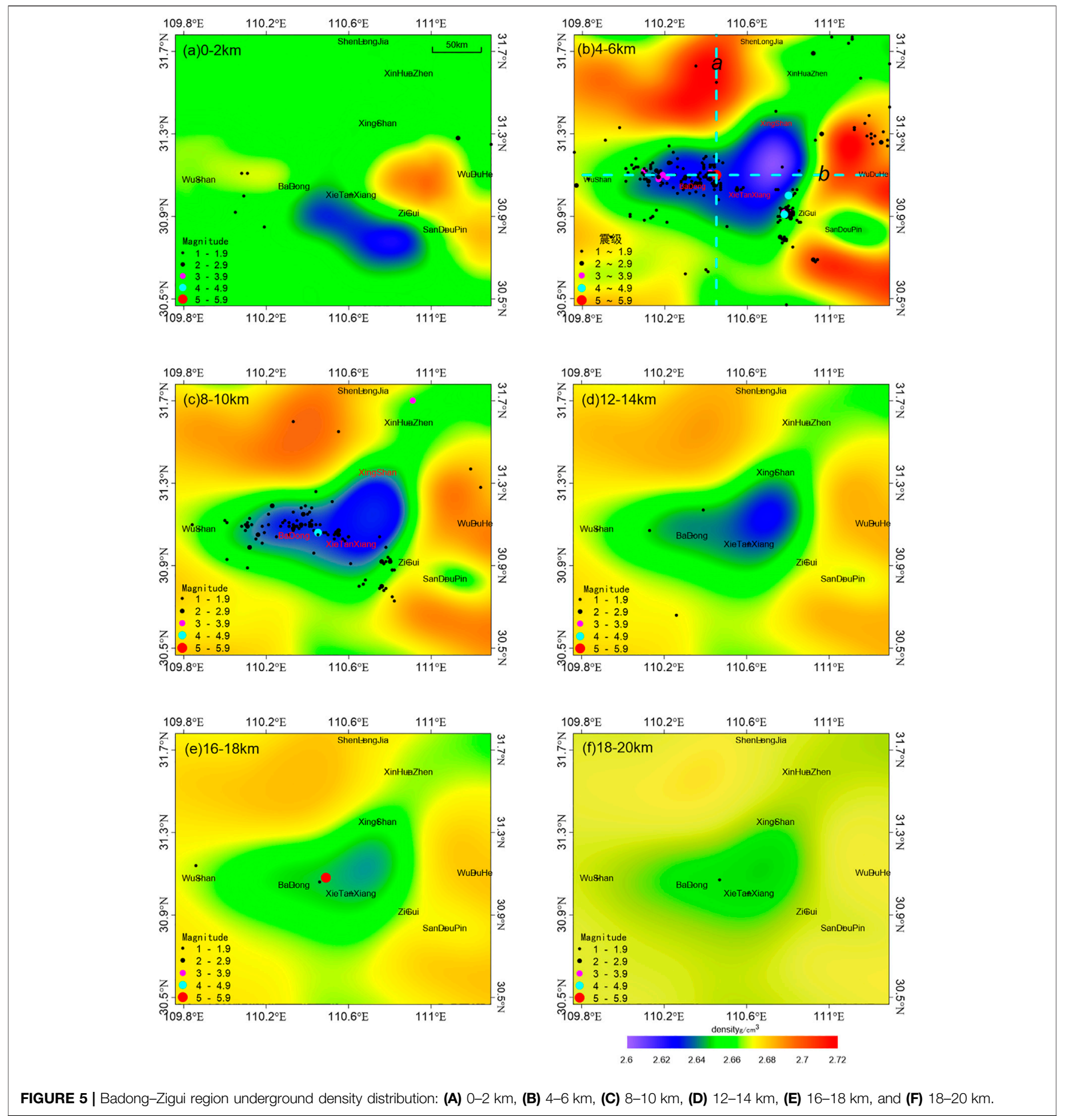

maximum depth in Figures 5E,F. The sedimentary depth at Zigui Basin is approximately $13-16 \mathrm{~km}$, and the crystalline base at Huangling is approximately $15-19 \mathrm{~km}$, which is greater than the tectonic depths of Li et al. (2010). This is due to the blur effect of the $\mathrm{L}_{2}$ norm, which is used in the inversion method. The anomaly inversion amplitude is small and flat, which makes the energy unfocused, resulting in a slight "inflation" of the profile.

\section{STRUCTURAL CHARACTERISTIC ANALYSIS}

The inversion results indicate that the sedimentary strata at the Zigui Basin are mainly carbonated rocks with fine clastic rocks in low density. Since the first Three Gorges Reservoir impoundment in May 2003, a large number of moderate and small earthquakes, and micro-seismic activities have occurred in the headland area. 
TABLE 2 | Focal mechanism solution of five earthquakes.

\begin{tabular}{|c|c|c|c|c|c|c|c|}
\hline & \multicolumn{2}{|c|}{ Epicenter $\mathrm{N}\left({ }^{\circ}\right) / \mathbf{E}\left({ }^{\circ}\right)$} & \multirow{2}{*}{$\begin{array}{l}\text { Ms } \\
5.1\end{array}$} & \multirow{2}{*}{$\begin{array}{c}\text { Depth (km) } \\
16\end{array}$} & \multirow{2}{*}{$\begin{array}{c}\text { Nodal plane1 } \\
296 / 73 /^{*}\end{array}$} & \multirow{2}{*}{$\begin{array}{c}\text { Nodal plane2 } \\
37 / 59 /^{*}\end{array}$} & \multirow{2}{*}{$\begin{array}{c}\text { Seismogenic nodal } \\
\text { plane } \\
37 / 60-80\end{array}$} \\
\hline 1979 Zigui & 31.08 & 110.49 & & & & & \\
\hline 2008 Zigui & 30.98 & 110.78 & 4.1 & 7 & 213/81/110 & $326 / 22 / 25$ & Nodal plane1 \\
\hline 2013 Badong & 31.09 & 110.42 & 5.1 & 5 & $117 / 28 /-136$ & $347 / 71 /-68$ & $265.5 / 85 /-120.7$ \\
\hline \multirow[t]{2}{*}{2014 Zigui } & 30.92 & 110.80 & 4.5 & 7.7 & 45/79/158 & 139/68/12 & Nodal plane1 \\
\hline & 30.91 & 110.82 & 4.9 & 9.1 & $46 / 68 / 164$ & $142 / 76 / 23$ & Nodal plane1 \\
\hline \multirow[t]{2}{*}{2017 Badong } & 31.03 & 110.44 & 4.3 & 3.8 & $160 / 88 / 45$ & $67 / 45 / 177$ & strike NEE/dip SE/ \\
\hline & 31.04 & 110.45 & 4.1 & 2.4 & $155 / 83 / 27$ & $62 / 63 / 173$ & pure strike-slip \\
\hline
\end{tabular}

The "*" indicates that the dip angle of the seismic nodal plane is unknown.

Most micro-seismic activity is spatially and temporally concentrated.

Since the Three Gorges seismic network was operated from 2001, the focal mechanism solution of moderate earthquakes in this area has been studied systematically. The seismic mechanism solutions for the five earthquakes obtained in this paper are shown in Table 2.

The 1979 Longhuiguan Ms 5.1 earthquake at Zigui has the property of left-rotation thrust fault and is a tectonic earthquake under the action of the regional tectonic stress field (Wang, 1981). The 2008 Zigui Ms 4.1 earthquake has the property of strike-slip and thrust and is related to the adjustment of tectonic stress field and the Xiannushan fault (Wei et al., 2013; Li et al., 2019). The 2013 Badong Ms 5.1 earthquake has the property of normal fault strike-slip under nearly east-westward, which belongs to the tectonic earthquake induced by reservoir (Chen et al., 2014). The 2014 Zigui Ms 4.5 and Ms 4.9 earthquakes are characterized by strike-slip and a small amount of thrust dislocation, and controlled and affected by Xiannvshan fault and Jiuwanxi fault activity (Wu et al., 2015). The 2017 Badong Ms 4.3 and Ms 4.1 earthquakes have the property of pure strike-slip. The seismogenic mechanism may be the shear dislocation caused by fracture and instability of Triassic limestone in the area due to long-term seepage and dissolution of reservoir water ( $\mathrm{Li}$ et al., 2019).

According to the focal mechanism solutions and the nodal planel information of the above five earthquakes, the local dislocation of the seismic fault at the source were projected onto the horizontal plane to obtain the local dislocations at the source of the five earthquakes. Then, the spatial distribution of the seismic sequence and the crustal movement trend of the source area were drew combined with the density inversion results (see Figure 6).

2 Ms 5.1 earthquakes and 4 Ms 4-5 earthquakes are all within the boundaries of Gaoqiao fault, Niukou-Zoujiashan fault and Jiuwanxi fault. Six earthquakes with epicenters close to each other, located west of the center of the Zigui Basin. In combination with Figure 6, it appears that this location is at the intermediate junction of high density in the west and low density in the east of the Zigui Basin. By processing the seismic wave parameters of 34 stations, Wang (1981) obtained the focal mechanism solution of the 1979 Longhuiguan earthquake at Zigui, and deduced that the nodal plane at $37^{\circ}$ north-east was the fault plane of the earthquake, with the property of left lateral and thrust fault. It should be formed by the NE-NNE uplift folds in the region during the Neotectonic period under the extrusion of tectonic stresses in the NW-NE of the region. For the 2013 Badong Ms 5.1 earthquake, the strike of seismogenic fault was $265.5^{\circ}$, and it can be judged that the focal mechanism was not caused by the Gaoqiao fault and Niukou-Zoujiashan fault. From the perspective of seismography (Chen et al., 2014), the dominant frequency and corner frequency of this earthquake are both low and have the characteristics of collapse earthquake, which indicates that this earthquake was related to the long-term leakage-related dissolution of the water in the Three Gorges reservoir. Based on the analysis of the activity characteristics of Badong Ms 4.3 and Ms 4.1 earthquake sequence in 2017, it is indicated that the unloading of reservoir water makes the compressive stress in this area rebound locally. Then it leads to the expansion of some cracks, and the fractured rock mass that causes dissolution of the reservoir water faces unstable sliding, which finally causes the earthquake. It can be considered that these two earthquakes are different from the tectonic earthquakes caused by the known faults in the region. Moreover, it can also be considered to be independent of the known faults in the region, from aftershock sequence distributions and nodal plane (strike and dip angle) of these two earthquakes. In addition, for the 2018 Zigui Ms 4.5 and Ms 4.1 earthquake, the motion trend of the epicenter region is in the SEE direction, and the aftershocks are also distributed in the SEE direction.

In combination with the analysis of the seismogenic structures of the four abovementioned earthquakes, the results were all considered inconsistent with the strike and dip angle of the existing faults in the area, which indicates that there was no fault structure consistent with the focal mechanism solution of the above earthquakes. From the geological point of view, the whole epicenter of the region is located in the stratigraphy of Badong Group of the middle Triassic and Jialingjiang-Daye Group of the lower Triassic. It has a significantly lower uniaxial compressive strength relative to both its overlying and underlying strata and is a soft substratum prone to slippage ( $\mathrm{Li}$ et al., 2018). Under the external factors such as long-term leakage dissolution and loading-unloading of the Three Gorges reservoir water, the regional cracks become unstable and slip, and then the earthquake occurs. The study of the tectonic characteristic of Zigui Basin shows that it is held by two anticlines in the north and east directions, the extension of the Sichuan basin in the west and the diffusion of the material density from east to west (Wang et al., 2019). As a whole, the basin has a pattern of mutual movement and extrusion from east to west. In recent 30 years, Ms 


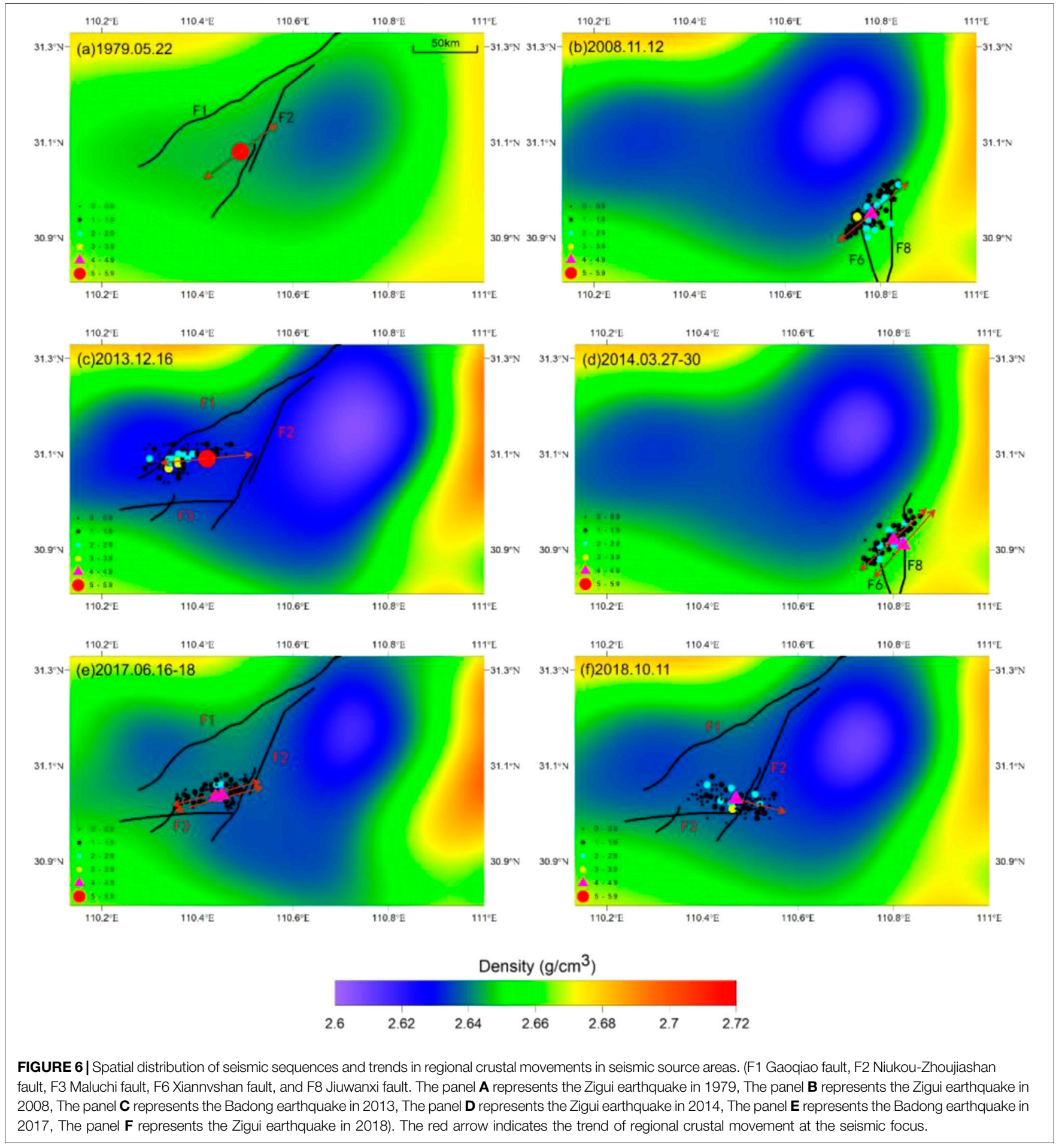

4-6 earthquakes occurred intensively in this local region, and it can be considered that the long-term accumulation of tectonic stress in this region is related to the continuous deposition of the Zigui Basin and the east-west material migration movement extrusion.

The 2008 Zigui Ms 4.1 earthquake, the 2014 Zigui Ms 4.5 and Ms 4.9 earthquakes are all located at the junction of high and low densities in the Zigui Basin and the peripheral Huangling Anticline as shown in Figures 6B,D. From a spatial perspective, three earthquakes occurred in a fork-shaped area at Xiannvshan fault and Jiuwanxi fault. While the Nodal plane strikes of these 3 Ms 4-5 earthquakes do not coincide with these two faults. The epicenter of the 2008 Ms 4.1 earthquake and 2014 Ms 4.5 earthquake are at the bottom of the sediment cover in the 
Zigui Basin, the epicenter of 2014 Ms 4.9 earthquake is within a basal crystalline granite or metamorphic layer. These lithologic strata are upper and Middle Triassic, Upper and lower Permian, upper and middle Silurian limestone, sandstone, and shale. This lithologic-stratigraphic distribution is conducive to reservoir erosion and infiltration. Under the tectonic background of the entire Chinese mainland being compressed by the Indian plate from north to northwest, the Three Gorges and adjacent areas have been moving in the SE direction in the past decades. It can be judged that the whole Zigui Basin has a movement trend in the SE direction; the slow uplifting denudation of the Cenozoic Huangling Anticline provides a material source for the continuous deposition of the Zigui Basin. It is believed that the accumulation of tectonic stress in the local region of the southeast edge of the Zigui Basin is formed by the slow uplifting of the Huangling Anticline and the motion extrusion in the SE direction of the Zigui Basin.

\section{CONCLUSION}

In this study, the 3D density structure of the Three Gorges and adjacent areas was obtained using the Bouguer gravity anomaly with regional geological and geophysical data. The Zigui Basin, part of the Huangling Anticline, Shenlongiia Uplift, and other large geological structural units could be seen clearly in the inversion results. The sedimentary layer of the Zigui Basin was shallow in the west and deep in the east, while the sediment density in the east was lower than that in the west. There was also an obvious low-density area in Xingshan-Xietan.

Four earthquakes of magnitude Ms 4-6 have occurred in the west of the core of the Zigui Basin, and the epicenters are relatively close to each other. In terms of density distribution, this area is at the junction of high and low density from east to west. The epicenter motion of the four moderate earthquakes trends in the NE, NEE, and SEE directions, and were all within the boundaries of the Gaoqiao fault, Niukou-Zoujiashan fault, and Jiuwanxi fault. The seismogenic structures were all inconsistent with the strike and dip angle of the existing faults in the area. As the local area is a soft substratum prone region where slippage occurs, the cracks progressively become unstable and slip, and

\section{REFERENCES}

Chen, J., Chen, Z., Jiang, L., Wu, H., Qiao, Y., and Jia, Z. (2014). On Causes of Badong Ms 5.1 Earthquake. J. Geodesy Geodynamics 34 (3), 10-14. doi:10.14075/ j.jgg.2014.03.029

Ge, X., Shen, C., Yang, Z., Mei, L., Xu, S., Peng, L., et al. (2013). Low-temperature Thermochronology Constraints on the Mesozoic-Cenozoic Exhumation of the Huangling Massif in the Middle Yangtze Block, Central China. J. Earth Sci. 24 (4), 541-552. doi:10.1007/s12583-013-0348-8

Gong, Z., Zhang, H., Li, Z., Luo, H., Luo, F., Liu, L., et al. (2014). The Sedimentation and Development Evolution of Zigui Basin. Resour. Environ. Eng. 28 (s1), 35-39. doi:10.16536/j.cnki.issn.1671-1211.2014.s1.007

Hu, S., Kohn, B. P., Raza, A., Wang, J., and Gleadow, A. J. W. (2006a). Cretaceous and Cenozoic Cooling History across the Ultrahigh Pressure Tongbai-Dabie belt, central China, from Apatite Fission-Track Thermochronology. Tectonophysics 420 (3-4), 409-429. doi:10.1016/j.tecto.2006.03.027 finally the earthquake occurs, owing to dissolution caused by long-term leakage and loading-unloading of the Three Gorges reservoir water. It can be concluded that the long-term accumulation of tectonic stresses in this localized area is related to the continuous sedimentation of the Zigui Basin and extrusion of material migratory movements in the east-west direction. The 2Ms 4-5 earthquakes that occurred in the southeast side of the Zigui Basin were local earthquakes triggered by the background of Huangling Anticline slow uplift denudation and eastward extrusion of the accumulated stress in the area.

According to the principle of clustering of small earthquakes, it could not be ruled out that there may be one or several NE and NEE small buried faults in the western core area of Zigui Basin, and one NE buried fault exists in the southeast margin of the basin, which was induced by the long-term infiltration of reservoir water and the effect of loading-unloading.

\section{DATA AVAILABILITY STATEMENT}

The raw data supporting the conclusion of this article will be made available by the authors, without undue reservation.

\section{AUTHOR CONTRIBUTIONS}

YW and JP conceived and designed the experiment; YW performed the computation; ZW and HY analyzed the data; YZ and JP interpreted the results; YW and JP discussed the results and polished the manuscript. YW and YZ wrote the paper and all the authors improved it.

\section{FUNDING}

This research was funded by the National Natural Science Fund of China $(41931074,41974096)$, the National Key Research and Development Project of China, Monitoring, Early Warning and Prevention of Major Natural Disasters (2018YFC1503503-01).

Hu, S., Raza, A., Min, K., Kohn, B. P., Reiners, P. W., Ketcham, R. A., et al. (2006b). Late Mesozoic and Cenozoic Thermotectonic Evolution along a Transect from the North China Craton through the Qinling Orogen into the Yangtze Craton, Central China. Tectonics 25 (6), a-n. doi:10.1029/ 2006TC001985

Jian, W., Chongyang, S., Hui, I., Shaoan, S., and Lelin, X. (2012). Gravity Inversion of Deep-Crust and Mantle Interfaces in the Three Gorges Area. Geodesy and Geodynamics 3 (4), 7-17. doi:10.3724/SP.J.1246.2012.0008

Jiang, F. (2004). Discussions on the Background of Tectonic Movement of Three-Gorge Region. Adv. Geodesy Geodynamics, 501-506.

Li, A., Han, X., and Xu, Y. (1987). Characteristics of Gravity Field in the Three-Gorge Region, Western Hubei Province and its Seismotectonic Significance. Seismology Geology. 9 (3), 73-80.

Li, J., Zhang, L., Liao, W., Zhao, Y., Wei, G., Yang, J., et al. (2018). Earthquakes in the Fold Structure-The Genesis of the M4.3 Earthquake Sequence in the Three Gorges Reservoir Area in 2017. Chin. J. Geophys. 61 (9), 3701-3712. doi:10.6038/ cjg2018L0756 
Li, J., Zhang, Y., Shi, W., Li, H., and Dong, S. (2009). Tectonic Deformation Features of Shennongjia Region Eastern Dabashan Foreland Structural Belt. J. Geomechanics 15 (2), 162-177. doi:10.3969/j.issn.10066616.2009.02.006

Li, Q., Zhao, X., Cai, J., and Liu, R. (2011). S-Wave Velocity Structure of Upper and Middle Crust beneath the Three Gorges Reservoir Dam and Adjacent Region. Acta Seismologica Sinica 33 (1), 39-50. doi:10.3969/j.issn.02533782.2011.01.004

Li, Q., Zhao, X., Cai, J., Liu, R., and Zhao, C. (2010). Study on Tectonic Environment of Deep Crust and Seismogenesis of Earthquakes beneath Main Three Gorges Reservoir Area. J. Geodesy Geodynamics 30 (5), 1-7. doi:10.14075/j.jgg.2010.05.018

Li, W., Chu, R., and Wang, S. (2019). Preliminary Discussion on the Seismogenic Mechanism of Ms 4.3 Earthquake in June 2017 in Zigui County, Hubei Province. Earthquake 39 (3), 28-42.

Li, Y., and Oldenburg, D. W. (1998). 3-D Inversion of Gravity Data. Geophysics 63 (1), 109-119. doi:10.1190/1.1444302

Li, Y., and Oldenburg, D. W. (1996). 3-D Inversion of Magnetic Data. Geophysics 61 (2), 394-408. doi:10.1190/1.1443968

Liang, X., Mao, X., Zeng, C., Hu, Z., Yang, Y., and Yu, W. (2016). Gravity Field Characteristics and Orogenic Belt Structure of the Qinling-Dabie Orogenic Belt (Hubei Section). Geology. China 43 (2), 446-457. doi:10.3969/j.issn.10003657.2016.02.007

Liu, L., Chen, X., Pan, L., and Gong, Z. (2016). Geochemical Characteristics and Petrogenesis of Dolomites from the Shicaohe Formation at Southern Shennongiia Uplift. Resour. Environ. Eng. 30 (4), 551-555. doi:10.16536/ j.cnki.issn.1671-1211.2016.04.002

Liu, S., Li, W., Wang, K., Qian, T., and Jiang, C. (2015a). Late Mesozoic Development of the Southern Qinling-Dabieshan Foreland Fold-Thrust belt, Central China, and its Role in Continent-Continent Collision. Tectonophysics 644-645, 220-234. doi:10.1016/j.tecto.2015.01.015

Liu, S., Liu, S., Jia, M., Zhang, H., Han, Y., and Zhang, D. (1984). The Deep Gravitational Field and its Geological Explanation over HuBei Province and Vicinal Regions. Crustal Deformation and Earthquake 4 (4), 357-364.

Liu, S., Steel, R., and Zhang, G. (2005). Mesozoic Sedimentary basin Development and Tectonic Implication, Northern Yangtze Block, Eastern China: Record of Continent-Continent Collision. J. Asian Earth Sci. 25 (1), 9-27. doi:10.1016/ j.jseaes.2004.01.010

Liu, S., Yang, C., Li, F., Liao, Z., Zhang, Q., and Chen, C. (2015b). Cause and Ore-Bearing Characteristics of Gold Deposit in Xiangxi-Western Hubei Metallogenic Belt of Huangling Anticline. Resour. Environ. Eng. 29 (2), 150-154. doi:10.16536/j.cnki.issn.1671-1211.2015.02.012

Oldenburg, D. W. (1974). The Inversion and Interpretation of Gravity Anomalies. Geophysics 39 (4), 526-536. doi:10.1190/1.1440444

Qu, H., Hu, J., Cui, J., Wu, G., Tian, M., Shi, W., et al. (2009). Jurassic Sedimentary Filling Process of Zigui Basin in the Eastern Section of Daba Mountain Tectonic Belt and its Structural Evolution. Acta Geol. Sinica 83 (9), 1255-1268. doi:10.3321/j.issn:0001-5717.2009.09.006

Qu, H., Kang, Y., and Cui, J. (2014). Late Mesozoic Sedimentary Basin Evolution and Tectonic Implication in Huangling Area, Northern of Yangtze Block. Chin. J. Geology. 49 (4), 1070-1092. doi:10.3969/ j.issn.0563-5020.2014.04.004

Shen, C.-B., Donelick, R. A., O'Sullivan, P. B., Jonckheere, R., Yang, Z., She, Z.-B., et al. (2012a). Provenance and Hinterland Exhumation from LA-ICP-MS Zircon U-Pb and Fission-Track Double Dating of Cretaceous Sediments in the Jianghan Basin, Yangtze Block, central China. Sediment. Geology. 281 (15), 194-207. doi:10.1016/j.sedgeo.2012.09.009

Shen, C., Li, A., and Gan, J. (1990). Airborne Magnetic Anomaly and Seismic Activity in the Three Gorges Region, West of HuBei Province. South China Seismological J. 10 (2), 62-67. doi:10.13512/j.hndz.1990.02.010

Shen, C., Mei, L., Min, K., Jonckheere, R., Ratschbacher, L., Yang, Z., et al. (2012b). Multi-chronometric Dating of the Huarong Granitoids from the Middle Yangtze Craton: Implications for the Tectonic Evolution of Eastern China. J. Asian Earth Sci. 52, 73-87. doi:10.1016/j.jseaes.2012.02.013
Wang, H., Hsu, H. T., and Zhu, Y. Z. (2002). Prediction of Surface Horizontal Displacements, and Gravity and Tilt Changes Caused by Filling the Three Gorges Reservoir. J. Geodesy 76 (2), 105-114. doi:10.1007/s00190-001$0228-3$

Wang, J. (1981). Focal Mechanism and Topographical Changes of the 1979 Badong Magnitude 5.1 Earthquake in Hubei. Crustal Deformation and Earthquake 1, 93-100.

Wang, J., Wang, Q., Huang, S., Wu, H., Zhao, L., and Chen, J. (2018a). Decollement Structures and Seismic Activity of Badong Area in Hubei Province. J. Geodesy Geodynamics 38 (3), 225-232. doi:10.14075/j.jgg.2018.03.002

Wang, K., Zhao, X., Deng, C., and Zhang, F. (2013a). Relationship between Landslide Type and Zuojituo Anticline Badong Fault in Three Gorges Reservoir Area. J. Jilin Univ. (Earth Sci. Edition) 43 (1), 169-177. doi:10.13278/j.cnki.jjuese.2013.01.036

Wang, L., Chen, C., Zou, R., and Du, J. (2014). Surface Gravity and Deformation Effects of Water Storage Changes in China's Three Gorges Reservoir Constrained by Modeled Results and In Situ Measurements. J. Appl. Geophys. 108, 25-34. doi:10.1016/j.jappgeo.2014.06.007

Wang, Q., Zhang, L., Liao, W., Li, J., and Shen, X. (2013b). Fault Tectonics and Seismic Activity Characteristics of Three Gorges Reservoir. J. Geodesy Geodynamics 33 (5), 29-33. doi:10.14075/j.jgg.2013.05.035

Wang, S., Zhu, S., and Li, R. (1992). Three Dimensional Inversion of Gravity Anomalies in the Region of Three Gorges, the Yangtze River. Acta Geophysica Sinica 35 (1), 69-76.

Wang, W., Zhang, C., Yang, Q., Zhou, Z., Zhu, J., and Kang, S. (2018b). Impact of Atmospheric Pressure Loading on Regional Crustal Deformation and Gravity Change. Geomatics Inf. Sci. Wuhan Univ. 43 (9), 1302-1308. doi:10.13203/ j.whugis 20160392

Wang, Ze. (2020). Crust Density Inversion and Tectonic Characteristics of BadongZigui Area[D]. Wuhan, China: Institute of Seismology China Earthquake Administration.

Wang, Z., Wu, Y., Zhang, Y., and Yao, Y. (2020). Crustal Density Inversion and its Tectonic Structure in Badong-Zigui Area. Geomatics Inf. Sci. Wuhan Univ. 45 (11), 1763-1770. doi:10.13203/j.whugis20190344

Wei, G., Zhang, L., Shen, X., and Chen, J. (2013). Study on Accurate Relocation of Earthquakes Near Zigui County in Three Gorges. J. Geodesy Geodynamics 33 (1), 68-75. doi:10.14075/j.jgg.2013.s1.037

Wu, H., Yao, Y., Shen, X., and Zhao, L. (2015). A Discussion on the Source and Seismogenic Structure of Ms 4.5 and Ms 4.7 Zigui Earthquakes in 2014. Seismology Geology. 37 (3), 719-730.

Wuhan Earthquake Engineering Research Institute (2010). The Seismic Safety Evaluation Report of the ZiguiXiangxihe Bridge Project Site.

Yang, G., Shen, C., Tan, H., Wu, G., and Wang, J. (2014). Isostatic Gravity Anomalies of Badong Region and Tectonic Activity. J. Geodesy Geodynamics 34 (3), 35-39. doi:10.14075/j.jgg.2014.03.035

Yu, W., Shen, C., and Yang, C. (2017). Constraints of Fission Track Dating on the Mesozoic-Cenozoic Tectonic-Thermal Evolution of the Zigui Basin. Earth Sci. Front. 24 (3), 116-126. doi:10.13745/j.esf.2017.03.010

Zeng, H. (2005). Gravity Field and Gravity Exploration. Beijing: Geological Publishing House.

Zhang, K. F., Featherstone, W. E., Bian, S. F., and Tao, B. Z. (1996). Time Variations of the Earth's Gravity Field and Crustal Deformation Due to the Establishment of the Three Gorges Reservoir. J. Geodesy 70 (7), 440-449. doi:10.1007/BF01090819

Zhang, L., Li, J., Sun, X., Liao, W., Zhao, Y., Wei, G., et al. (2018). A Possible Mechanism of Reservoir-Induced Earthquakes in the Three Gorges Reservoir, Central China. Bull. Seismological Soc. America 108 (5B), 3016-3028. doi:10.1785/0120180015

Zhang, Y., Chen, C., Liang, Q., Wang, L., Du, J., and Liu, S. (2012). Density Structure of Upper and Middle Crust in Three Gorges Reservoir Area. Earth Science-Journal China Univ. Geosciences 37 (s1), 213-222. doi:10.3799/ dqkx.2012.S1.022

Zhang, Y., Lv, P., and Liu, J. (2017). Impact of the Yangtze River Three Gorges Reservoir on Fault Activity. Geomatics Inf. Sci. Wuhan Univ. 42 (10), 1497-1500. doi:10.13203/j.whugis20140983 
Zhang, Y., Yan, J., Li, F., Chen, C., Mei, B., Jin, S., et al. (2015). A New Bound Constraints Method for 3-D Potential Field Data Inversion Using Lagrangian Multipliers. Geophys. J. Int. 201 (1), 267-275. doi:10.1093/gji/ ggv016

Conflict of Interest: The authors declare that the research was conducted in the absence of any commercial or financial relationships that could be construed as a potential conflict of interest.

Publisher's Note: All claims expressed in this article are solely those of the authors and do not necessarily represent those of their affiliated organizations, or those of the publisher, the editors and the reviewers. Any product that may be evaluated in this article, or claim that may be made by its manufacturer, is not guaranteed or endorsed by the publisher.

Copyright (c) $2021 \mathrm{Wu}$, Pei, Wang, Zhang and Yuan. This is an open-access article distributed under the terms of the Creative Commons Attribution License (CC BY). The use, distribution or reproduction in other forums is permitted, provided the original author(s) and the copyright owner(s) are credited and that the original publication in this journal is cited, in accordance with accepted academic practice. No use, distribution or reproduction is permitted which does not comply with these terms. 